\title{
$\ll$ Research Note» \\ Characterization of Chicken Portomicron Remnant and Very Low Density Lipoprotein Remnant
}

\author{
Kan Sato ${ }^{1}$, Katsumi Suzuki ${ }^{2}$ and Yukio Akiba ${ }^{2}$ \\ ${ }^{1}$ Department of Biological Production, Tokyo University of Agriculture and Technology, Fuchu-shi, Tokyo,183-8509, Japan \\ ${ }^{2}$ Graduate School of Agricultural Science, Tohoku University, Aoba-ku, Sendai-shi, 981-8555, Japan
}

\begin{abstract}
Portomicron remnant and very low density lipoprotein (VLDL) remnant in chickens were prepared by the method using ultracentrifugation $(\mathrm{d}<1.019)$ following an in vitro incubation of portomicron or VLDL prepared from chicken plasma with chicken lipoprotein lipase (LPL) for $2 \mathrm{~h}$ at $37^{\circ} \mathrm{C}$. The portomicron remnants and VLDL remnants yielded the almost single peak in the elution pattern on Bio-Gel A50m column $(1.6 \times 50 \mathrm{~cm})$ and the particle sizes were smaller than portomicron and VLDL since the elution of remnants by Bio-Gel A50m was similar to LDL rather than portomicron and VLDL. Chicken remnants had low triacylglycerol contents with high cholesterol and lower apolipoprotein C contents compared to portomicron or VLDL. These findings present the possible procedure to prepare in vitro chicken LPL-generated portomicron- and VLDL-remnants and suggested that the chicken remnants are characterized by a peculiar apolipoprotein composition while resemble to mammalian remnants in the lipid composition and particle size.
\end{abstract}

Abbreviations: VLDL, very low density lipoprotein; LDL, low density lipoprotein; Apo, apolipoprotein; LPL, lipoprotein lipase

Key words: broiler chicken, lipoprotein, lipoprotein lipase, portomicron remnant, VLDL remnant

J. Poult. Sci., 46: 35-39, 2009

\section{Introduction}

The obligatory step in the transport of triacylglycerol fatty acids from circulating chylomicron and very low density lipoprotein (VLDL) into tissues is hydrolysis of triacylglycerol core in the lipoprotein particles by lipoprotein lipase (LPL, EC 3.1.1.3) (Nilsson-Ehle et al., 1980). In mammals, plasma chylomicron and VLDL are converted to their remnants, respectively, following LPL hydrolysis with taking off the certain apolipoproteins (Havel et al., 1980). The chylomicron remnants are cleared rapidly from plasma and taken up mainly by low density lipoprotein (LDL) receptor-related protein (LRP) and LDL receptor (Martins et al., 2000), and the clearance is mediated by apolipoprotein (Apo) E and Apo B, respectively. In contrast, VLDL remnants are mainly converted to LDL and taken up by liver through the LDL receptor (Ginsberg, 1998). These findings have been reported practically in experiments on liver membrane binding of lipoproteins generated by milk LPL (Hui et al., 1984), post-heparin plasma (Windler et al., 1988) or remnant- like lipid emulsion (Martins et al., 2000) in mammals.

Received: August 20, 2008, Accepted: October 30, 2008

Correspondence: Dr. K. Sato, Tokyo University of Agriculture and Technology, Fuchu-shi, Tokyo, 183-8509, Japan.

(E-mail: satokan@cc.tuat.ac.jp)
In chickens, VLDL/vitellogenin receptor (LR8) (95 and $105 \mathrm{kDa})$ and LRP1 $(515 \mathrm{kDa})$ in the ovary (Schneider et al., 2007) and LDL receptor in liver (Hummel et al., 2003) were identified. There is, however, less information on the lipoprotein metabolism following hydrolysis of portomicron (chylomicron is referred to as portomicron in avians.) and VLDL by LPL. In addition, chicken portomicron remnant and VLDL remnant were not characterized until now. Griffin et al. (1992) reported that only 6$7 \%$ of portomicron and VLDL triacylglycerols were taken up by the abdominal adipose tissues in broiler chickens. We demonstrated that chicken LPL plays a crucial role for fat accumulation in adipose tissues and the inhibition of LPL catalyzed hydrolysis of triacylglycerol-rich lipoproteins reduces the fat accumulation in chickens (Sato $e t$ al., 1999), and also characterized that the chicken-LPL had high Vmax with low $\mathrm{Km}$ as compared to rat-LPL (Sato et al., 1997). These findings suggested that the most of VLDL and portomicron hydrolyzed by LPL were converted to remnants to be taken up to the liver by the lipoprotein receptor-mediated endocytosis in chickens, then were resynthesised to newly triacylglycerol rich lipoprotein. In addition, Rajavashisth et al. (1987) observed that the chicken lipoprotein lacked apolipoprotein (apo) E which was found in mammals. In mammals, apo E plays an important role in the metabolism of triacylglycerol-rich lipoproteins, such as VLDL, chylomicrons, and chylomicron 
remnants, which mediate the high-affinity binding of apo E-containing lipoproteins to the LDL receptor and members of its gene family, including LRP, VLDL receptor, and the apo E2 receptor (apo E2R) (Cooper, 1997). These data may imply that there is a species difference between chickens and rats in lipoprotein metabolism following LPL catalyzed hydrolysis, especially in the viewpoint of apo $\mathrm{E}$ mediate endocytosis in mammals. From a viewpoint to investigate the lipoprotein receptor-mediated endocytosis in chicken lipoprotein remnants, it seems essential to provide the chemical characterization of chicken lipoprotein remnants, which may be generated through chicken adipose tissue LPL-catalyzed hydrolysis.

In the present work with broiler chickens, in order to characterize the lipoprotein metabolism following LPL catalyzed hydrolysis, we show the preparation and characterization of chicken portomicron remnant and VLDL remnant in vitro.

\section{Materials and Methods}

\section{Animals}

Male broiler chickens (Ross strain, Matsumoto Hatchery, Zao or Ibaragi, Japan) with body weight ranging from 1,500 to $2,000 \mathrm{~g}$ were provided. Chickens were fed ad libitum on a commercial grower's diet for broiler chickens. The blood was collected from the wing vein with EDTA $(1 \mathrm{mg} / \mathrm{ml})$, an anticoagulant, and centrifuged for $15 \mathrm{~min}$ at $1,500 \times \mathrm{g}$. After the blood collection, chickens were killed by cervical dislocation and abdominal adipose tisues were rapidly removed and chilled in ice-cold $\mathrm{NaCl}$ $(0.157 \mathrm{M})$. All procedures were approved by the "Animal Care and Use Committee" of the Graduate School of Agricultural Science of Tohoku University or Tokyo University of Agriculture and Technology.

\section{Preparation of Chicken $L P L$}

Acetone powders were prepared from adipose tissues of chickens according to the method of Sato et al. (1997). The crude LPL were prepared by an extraction of the acetone powders with $5 \mathrm{mM}$ sodium barbital buffer $(\mathrm{pH}$ 7.5) containing $0.5 \mathrm{M} \mathrm{NaCl}$.

Preparation of Portomicron Remnant and VLDL Remnant

Plasma lipoproteins, portomicron $(\mathrm{d}<0.96)$, VLDL (d 0.96-1.016) and LDL (d 1.019-1.063), were prepared by the method of Lindgren (1975) and Hermier et al. (1985) using ultracentrifugation performed HITACHI himac CP 56GII ultracentrifuges (Hitachi Koki, Tokyo, Japan) with a RP65T rotor.

Remnants of lipoproteins, portomicron and VLDL, were prepared by the method of Hui et al. (1984) with slight modifications. Portomicron and VLDL (containing $12 \mathrm{mg}$ triacylglycerols) were incubated for $2 \mathrm{~h}$ at $37^{\circ} \mathrm{C}$ in a solution containing $10 \mathrm{~m} l$ of crude chicken LPL $(4 \mathrm{mg}$ protein) and $10 \mathrm{ml}$ of $100 \mathrm{mM}$ Tris-HCl buffer ( $\mathrm{pH} \mathrm{8.6)} \mathrm{con-}$ taining $4 \%$ fatty acid-free albumin. This incubation condition was determined by our previous report (Sato et al., 1995). At the end of incubation, the solution was adjusted to a density of 1.063 with solid $\mathrm{KBr}$, overlayered with $2 \mathrm{ml}$ of saline/EDTA with $\mathrm{KBr}(\mathrm{d}=1.019)$, and remnants were refloated in a RP65T rotor by centrifugation for $16 \mathrm{hr}$ at $45,000 \mathrm{rpm}$. The isolated remnants were exchanged for $50 \mathrm{mM}$ Tris- $\mathrm{HCl}$ buffer ( $\mathrm{pH}$ 8.6) by PD-10 column (GE healthcare, Uppsala, Sweden).

\section{Characterization of Remnants}

To determine the remnant particle size and polity, lipoproteins were applied to a Bio-Gel A-50m (Bio-Rad Laboratories, CA, USA) column $(1.6 \times 50 \mathrm{~cm})$, eluted with 0.15 $\mathrm{M} \mathrm{NaCl}$ containing $1 \mathrm{mM}$ EDTA.

The different classes of lipids in lipoproteins were quantified according to colorimetric methods of triacylglycerol, phospholipid and total cholesterol followed by Fletcher (1968), Takayama et al. (1977) and Richmond (1974), respectively.

Electrophoretic evaluation of portomicron remnant and VLDL remnant apolipoproteins were made using SDSPAGE (10\% gel) by the method of Bouziane et al. (1994) after partial delipidation. Electrophoresis was performed in a Mini-PROTEAN II electrophoresis cell (Bio-Rad Laboratories, CA, USA) at $4^{\circ} \mathrm{C}$, for $1.5 \mathrm{hr}$ with $25 \mathrm{~mA} / \mathrm{gel}$ slab. The gels were then stained with Coomassie brilliant blue $\mathrm{G}$ 250.

\section{Other Assays}

The protein contents of enzyme and lipoproteins were determined by the method of Lowry et al. (1951) or Coomassie protein assay reagent (Pierce) using bovine serum albumin as the standard.

\section{Statistics}

A computer generated SAS applications package was used for statistical calculations (Statistical Analysis System Version 6.03, SAS Institute Inc., Cary, NC). Group data for multiple comparisons were analyzed by ANOVA using a general linear models procedure followed by Duncan's multiple rang test to test for differences among lipoproteins. The level of significance used in all studies was $p<0.05$.

\section{Results}

\section{Isolation of Chicken Portomicron Remnant and VLDL Remnant}

The chicken portomicron remnants and VLDL remnants isolated by the centrifugation were applied to BioGel A-50 m. The portomicron remnants and VLDL remnants were eluted as the almost single peak at $80-110 \mathrm{ml}$ of elution volume and these peaks were almost comparable to a peak obtained by the elution of chicken LDL (Fig. 1).

\section{Characteristics of Remnants}

Portomicron- and VLDL-remnants were characterized in lipid composition by significantly lower triacylglycerol but higher cholesterol contents than the corresponding native counterparts (Table 1). LDL contained low triacylglycerols with high phospholipids and total cholesterols as compared to portomicron- and VLDL-remnants.

Four major apolipoprotein bands, apo B100, apo A-I, apo $\mathrm{C}$ and apo A-IV, were detected on SDS-PAGE analysis of lipoproteins (Fig. 2). The lipoprotein remnants 

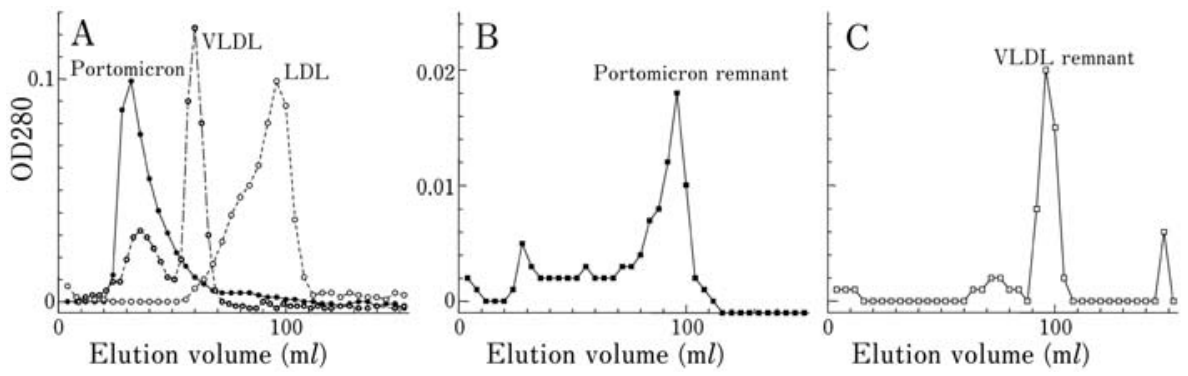

Fig. 1. The elution patterns of (A) no modified lipoproteins (portomicron $(\mathbf{O})$, VLDL(O) or $\operatorname{LDL}(\bigcirc)$, (B) portomicron $\operatorname{remnant}(\square)$, and (C) VLDL remnant $(\square)$ from Bio-Gel A50m.

Lipoproteins prepared from chicken plasma were then applied to a Bio-Gel A$50 \mathrm{~m}$ (Bio-Rad) column $(1.6 \times 50 \mathrm{~cm})$, eluted with $0.15 \mathrm{M} \mathrm{NaCl}$ containing 1 mM EDTA.

Table 1. Lipid composition in lipoproteins of chickens

\begin{tabular}{cccr}
\hline \hline & \multicolumn{3}{c}{$\%$ of total lipid } \\
\cline { 2 - 4 } & TG & PL & \multicolumn{1}{c}{ TC } \\
\hline Portomicron & $83.9 \pm 3.2^{\mathrm{a}}$ & $11.0 \pm 5.5^{\mathrm{b}}$ & $5.1 \pm 0.8^{\mathrm{e}}$ \\
Portomicron remnant & $73.9 \pm 4.3^{\mathrm{b}}$ & $14.6 \pm 4.2^{\mathrm{b}}$ & $11.5 \pm 1.2^{\mathrm{d}}$ \\
VLDL & $64.5 \pm 1.5^{\mathrm{c}}$ & $16.3 \pm 3.2^{\mathrm{b}}$ & $19.2 \pm 2.3^{\mathrm{c}}$ \\
VLDL remnant & $59.7 \pm 1.2^{\mathrm{d}}$ & $13.8 \pm 4.8^{\mathrm{b}}$ & $26.5 \pm 3.8^{\mathrm{b}}$ \\
LDL & $15.7 \pm 1.4^{\mathrm{e}}$ & $36.0 \pm 2.5^{\mathrm{a}}$ & $48.3 \pm 5.6^{\mathrm{a}}$ \\
\hline
\end{tabular}

Results are expressed as mean proportion ( $\%$ of weight) \pm SD of total lipids with five preparations for each group.

Values with different superscripts in columns are significantly different $(p<0.05)$.

$\mathrm{TG}=$ triacylaglycerol. $\mathrm{PL}=$ phospholipid. $\mathrm{TC}=$ Total cholesterol.

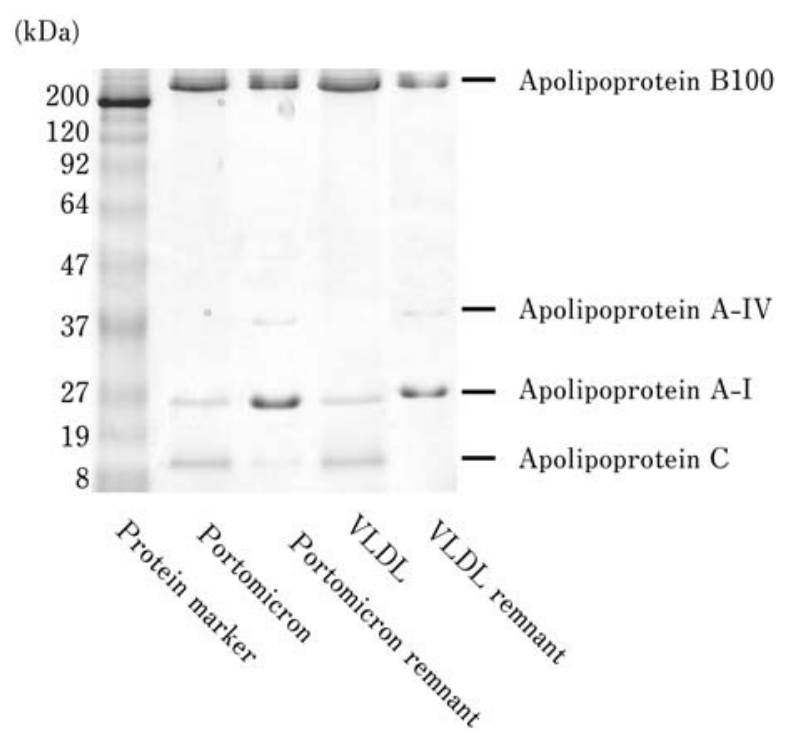

Fig. 2. Apolipoprotein distribution in lipoproteins of chickens. Lipoproteins after partial delipidation were applied to $10 \%$ polyacrilamide gel electrophoresis with sodium dodecyl sulfate (SDS-PAGE) and loaded. The gels were stained with Coomassie brilliant blue G250. were characterized by significantly lower apo $\mathrm{C}$ contents than the corresponding native counterparts with the comparable proportion of apo B100. The apo A-I and A-IV contents tended to be higher in the remnants than in portomicron and VLDL (Fig. 2).

\section{Discussion}

The present data showed that chicken lipoprotein remnants (potomicron remnants and VLDL remnants) could be prepared by in vitro partial hydrolysis of chicken lipoproteins by LPL prepared from chicken adipose tissue. The lipoprotein remnants have been largely prepared and characterized through in vitro incubation of serum lipoproteins with milk-LPL or post-heparin plasma in mammals (Havel et al., 1980). It is, however, preferable to provide LPL prepared from adipose tissue of respective species instead of milk-LPL or post-heparin plasma on a viewpoint to characterize the remnants in detail. The chicken LPL-generated remnants were eluted as the almost single peak by Bio-Gel A50m gel chromatography. Hui et al. (1984) reported that dog chylomicron remnants were prepared by the overnight incubation of chylomicrons with purified milk LPL in which $92 \%$ of the triacylglycerols in the dog chylomicrons were hydrolysed. In the preparation of chicken lipoprotein remnants based on the proce- 
dure of Hui et al. (1984) with the overnight incubation, gel chromatography analysis revealed the similar broad peaks together with portomicron- and VLDL-remnants (data not shown). Our previous study described that the in vitro hydrolysis of plasma portomicron and VLDL by chicken LPL increased linearly with the incubation time to attain the plateau at 50 min (Sato et al., 1995). In addition, we showed that chicken-LPL purified from adipose tissue had high Vmax with low apparent $\mathrm{Km}$ as compared to rat-LPL (Sato et al., 1997). It is, therefore, likely that incubation for $2 \mathrm{~h}$ with chicken LPL employed in the present study is relevant for the in vitro preparation of chicken remnants and thereby generated the remnants with single peak by Bio-Gel A50m conducted successively.

Chylomicron remnants and VLDL remnants in mammals are characterized by the decreases in triacylglycerol contents, Apo $\mathrm{C}$ proteins and particle sizes as compared to chylomicron and VLDL, respectively, while the increases in cholesteryl esters and phospholipids (Havel et al., 1980). In the present study, chicken portomicron- and VLDLremnants were characterized in the lipid composition by significantly lower triacylglycerol with the higher cholesterol contents than the corresponding native counterparts while by significantly higher triacylglycerol with the lower cholesterol contents than LDL. These results showed that the lipid compositions of chicken remnants were similar to those of mammals. The elution pattern of chicken lipoprotein remnants was similar to that of LDL in the present study despite there are marked differences in the lipid composition between remnants and LDL. Chicken remnants prepared in vitro in the present experiment demonstrated the delayed elution as compared to portomicron and VLDL. These results, therefore, indicate that the diameter of chicken remnants were smaller than that of portomicron and VLDL but equal to that of LDL. Mjos et al. (1975) reported that the diameter of remnants was smaller than that of chylomicrons and VLDLs in rats.

The present study showed that LPL-generated remnants had almost comparable apo B100 contents while lower apo $\mathrm{C}$ contents as compared to portomicron and VLDL. These findings might indicate that the partial hydrolysis of lipoproteins by LPL released apo $\mathrm{C}$ but not apo A-I and apo A-IV (Fig. 2). Windler et al. (1988) reported that the in the preparation of rat chylomicron remnants, the apo B48 and apo E contents were not changed whereas apo A-I, apo A-IV and apo C contents were decreased by LPL-catalyzed hydrolysis. These results suggested that there were species differences in content and function of apo A-I and A-IV in the apolipoproteins between chickens and mammals. In mammals, the clearance of chylomicron remnants is mediated by apo E (Borensztain et al., 1982). Rajavashisth et al. (1987) observed, however, that the chicken lipoprotein lacked Apo E which was found in mammals. It has been reported that apoB is a ligand of chicken lipoprotein receptors (Schneider, 2007). It is, therefore, suggested that chicken apo B100 might be functional as the ligand of the lipoprotein remnant receptors.
Our study showed that the preparation and characterization of chicken portomicron remnant and VLDL remnant in vitro to characterize lipoprotein metabolism following LPL catalyzed hydrolysis in chickens. As the chicken portomicron remnants and VLDL remnants appeared similar characteristics to mammalian remnants except the major apolipoprotein content, it is likely that the chicken remnants are incorporated, in part, by receptor mediated pathway as in mammals. Further investigation on chicken lipoprotein receptor using remnants prepared by the present study may provide possible clues to understand the lipoprotein metabolism following LPL catalyzed hydrolysis in chickens.

\section{Acknowledgments}

This work was partly supported by Grants-in-Aid (No. 20580302) from the Ministry of Education, Science and Culture of Japan.

\section{References}

Borensztain J, Getz GS, Padley RJ and Kotlar TJ. The apolipoprotein B-independent uptake of chylomicron remnants. Biochemical Journal, 204: 609-612. 1982.

Bouziane M, Prost J and Belleville J. Changes in fatty acid compositions of total serum and lipoprotein particles, in growing rats given protein-deficient diets with either hydrogenated coconut oils as fat sources. British Journal of Nutrition, 71: 375-387. 1994.

Cooper AD. Hepatic uptake of chylomicron remnants. Journal of Lipid Research, 38: 2173-2192. 1997.

Fletcher MJ. A colorimetric method for estimating serum triglycerides. Clinica Chimica Acta, 22: 393-395. 1968.

Ginsberg HN. Lipoprotein physiology. Endocrinology and Metabolism Clinics of North America, 27: 503-519. 1998.

Griffin HD, Guo K, Windsor D and Butterwith SC. Adipose tissue lipogenesis and fat deposition in leaner broiler chickens. Journal of Nutrition, 122: 363-368. 1992.

Havel RJ, Goldstein JL and Brown MS. Metabolic control and disease. (Bondy PK and Rosenberg LE eds.). pp. 393-494. Saunders Co., Philadelphia, USA. 1980.

Hermier D, Forgez P and Chapman MJ. A density gradient study of the lipoprotein and apolipoprotein distribution in the chicken, Gallus domesticus. Biochimica et Biophysica Acta, 836: 105-118. 1985.

Hui DY, Innerarity TL, Milne RW, Marcel YL and Mahley RW. Binding of chylomicron remnants and beta-very low density lipoproteins to hepatic and extrahepatic lipoprotein receptors. A process independent of apolipoprotein B48. Journal of Biological Chemistry, 259: 15060-15068. 1984.

Hummel S, Lynn EG, Osanger A, Hirayama S, Nimpf J and Schneider WJ. Molecular characterization of the first avian LDL receptor: role in sterol metabolism of ovarian follicular cells. Journal of Lipid Research, 44: 1633-1642. 2003.

Lindgren FT. In analysis of lipid and lipoprotein. (Perkins EG eds.). pp. 204-224., American Oil Chemists' Society, Champaign, Illinois, USA. 1975.

Lowry OH, Rosebrough NJ, Farr AL and Randall RJ. Protein measurement with the Folin phenol reagent. Journal of Biological Chemistry, 193: 265-275. 1951.

Martins IJ, Hone E, Chi C, Seydel U, Martins RN and Redgrave 
TG. Relative roles of LDLr and LRP in the metabolism of chylomicron remnants in genetically manipulated mice. Journal of Lipid Research, 41: 205-213. 2000.

Mjos OD, Faergeman O, Hamilton RL and Havel RJ. Characterization of remnants produced during the metabolism of triglyceride-rich lipoproteins of blood plasma and intestinal lymph in the rat. Journal of Clinical Investigation, 56: 603615. 1975.

Nilsson-Ehle P, Garfinkel AS and Schotz MC. Lipolytic enzymes and plasma lipoprotein metabolism. Annual Review of Biochemistry, 49: 669-693. 1980.

Rajavashisth TB, Dawson PA, Williams DL, Shackelford JE, Lebherz $\mathrm{H}$ and Lusis AJ. Structure, evolution, and regulation of chicken apoprotein A-1. Journal of Biological Chemistry, 262: 7058-7065. 1987.

Richmond W. Proceeding: The development of enzymic technique for the assay of cholesterol in biological fluids. Clinical Science and Molecular Medicine, 46: 6-7. 1974.

Sato K, Akiba Y, Kimura S and Horiguchi M. Species differences between chicks and rats in inhibition of lipoprotein hydro- lysis by Triton WR-1339. Comparative Biochemistry and Physiology. C, 112: 315-319. 1995.

Sato K, Akiba Y and Horiguchi M. Species differences between chickens and rats in chemical properties of adipose tissue lipoprotein lipase. Comparative Biochemistry and Physiology. A, 118: 855-858. 1997.

Sato K, Akiba Y, Chida Y and Takahashi K. Lipoprotein hydrolysis and fat accumulation in chicken adipose tissues are reduced by chronic administration of lipoprotein lipase monoclonal antibodies. Poultry Science, 78: 1286-1291. 1999.

Schneider WJ. Low density lipoprotein receptor relatives in chicken ovarian follicle and oocyte development. Cytogenetic and Genome Research, 117: 248-255. 2007.

Takayama M, Itoh S, Nagasaki T and Tanimizu I. A new enzymatic method for determination of serum choline containing phospholipids. Clinica Chimica Acta, 79: 93-98. 1977.

Windler E, Greeve J, Daerr WH and Greten H. Binding of rat chylomicrons and their remnants to hepatic low-densitylipoprotein receptor and its role in remnant removal. Biochemical Journal, 252: 553-561. 1988. 